\title{
Iron deficiency anemia among children aged 2-5 years in southern Ethiopia: a community based cross-sectional study
}

\author{
Alemselam Zebdewos Orsango ${ }^{\text {Corresp., }{ }^{1,2}, \text { Wossene Habtu }}{ }^{3}$, Tadesse Lejisa ${ }^{4}$, Eskindir Loha ${ }^{1,2,5}$, Bernt Lindtjørn $^{1,2}$, \\ Ingunn Marie S. Engebretsen ${ }^{2}$ \\ ${ }^{1}$ School of Public Health, College of Medicine and Health Sciences, Hawassa University, Hawassa, Ethiopia \\ 2 Centre for International Health, University of Bergen, Bergen, Norway \\ 3 Ethiopian Public Health Institute, Addis Ababa University, , Addis Ababa,, Ethiopia \\ 4 Ethiopian Public Health Institute, Addis Ababa University,., Addis Ababa, Ethiopia \\ ${ }^{5}$ Chr. Michelsen Institute,, Bergen, Norway \\ Corresponding Author: Alemselam Zebdewos Orsango \\ Email address: zalemselam@yahoo.com
}

Background: Iron-deficiency anemia (IDA) is a common type of nutritional anemia in lowincome countries, including Ethiopia. However, there is limited data on iron deficiency anemia prevalence and associated factors in Ethiopia, particularly for children aged 2 to 5 years. Objectives: To establish the prevalence of iron deficiency anemia and associated risk factors, focusing on iron-rich food consumption among children aged 2 to 5 years in southern Ethiopia. Methods: A community-based cross-sectional study was conducted in southern Ethiopia in 2017, involving 331 randomly selected children aged 2 to 5 years old. A structured questionnaire was used to collect information about the children and the households. Venous blood was collected from each child in a test tube to measure hemoglobin, ferritin, and C-reactive protein (CRP). Hemoglobin levels were determined using Hemocue ${ }^{\circledR} 301$ and adjusted for altitude. Anemia was defined as hemoglobin levels $<11 \mathrm{~g} / \mathrm{dl}$. Ferritin was adjusted for inflammation based on CRP concentration and low ferritin concentration defined as adjusted ferritin concentration $<12 \mu \mathrm{g} / \mathrm{L}$. IDA was considered when a child had both hemoglobin level $<11 \mathrm{~g} / \mathrm{dl}$ and low ferritin concentration. Bi-variable and multivariable logistic regression models were performed to identify factors associated with IDA and iron-rich food consumption. Results: The prevalence of iron deficiency anemia was $25 \%$, and the total anemia prevalence was $32 \%$. Only $15 \%$ of children consumed iron-rich foods in the preceding 24 hours, and $30 \%$ of children consumed iron-rich foods at least once in the preceding week. IDA decreased as the height for age z-score increased (Adjusted Odds Ratio 0.7; 95\% Cl 0.5-0.9). Mothers with increased educational level (AOR 1.1; 1.0-1.2) and households with increased dietary diversity (AOR 1.4; 1.2-1.6) consumed more iron-rich foods. Conclusions: Iron deficiency anaemia was a moderate public health problem in southern Ethiopia, and the iron-rich food 
consumption was low. Interventions should focus on food supplementation and fortification, food diversification and nutritional education, and promoting women's education. Keywords: Iron deficiency anemia, serum ferritin adjustment, and iron-rich food consumption. 
1 Iron deficiency anemia among children aged 2-5 years in southern Ethiopia: a

2 community based cross-sectional study

3

4

5

6 Alemselam Z Orsango, ${ }^{1,2 *}$ Wossene Habtu, ${ }^{3}$ Tadesse Lejisa, ${ }^{3}$ Eskindir Loha, ${ }^{1,2,4}$ Bernt

7 Lindtjørn, ${ }^{1,2}$ Ingunn Marie Stadskleiv Engebretsen ${ }^{2}$

8

9

10

1. School of Public Health, College of Medicine and Health Sciences, Hawassa University,

12 Hawassa, Ethiopia

13 2. Centre for International Health, University of Bergen, Bergen, Norway

14 3. Ethiopian Public Health Institute, Addis Ababa University, Addis Ababa, Ethiopia

4. Chr. Michelsen Institute, Bergen, Norway

16

* Corresponding author:

Alemselam Z Orsango; E-mail address:zalemselam@yahoo.com; Fax: +251 046220 8755;

Phone: +251911000961 


\section{Abstract}

Background: Iron-deficiency anemia (IDA) is a common type of nutritional anemia in lowincome countries, including Ethiopia. However, there is limited data on iron deficiency anemia prevalence and associated factors in Ethiopia, particularly for children aged 2 to 5 years.

Objectives: To establish the prevalence of iron deficiency anemia and associated risk factors, focusing on iron-rich food consumption among children aged 2 to 5 years in southern Ethiopia. Methods: A community-based cross-sectional study was conducted in southern Ethiopia in 2017, involving 331 randomly selected children aged 2 to 5 years old. A structured questionnaire was used to collect information about the children and the households. Venous blood was collected from each child in a test tube to measure hemoglobin, ferritin, and C-reactive protein (CRP). Hemoglobin levels were determined using Hemocue ${ }^{\circledR 3} 301$ and adjusted for altitude. Anemia was defined as hemoglobin levels $<11 \mathrm{~g} / \mathrm{dl}$. Ferritin was adjusted for inflammation based on CRP concentration and low ferritin concentration defined as adjusted ferritin concentration $<12 \mu \mathrm{g} / \mathrm{L}$. IDA was considered when a child had both hemoglobin level $<11 \mathrm{~g} / \mathrm{dl}$ and low ferritin concentration. Bi-variable and multivariable logistic regression models were performed to identify factors associated with IDA and iron-rich food consumption. Results: The prevalence of iron deficiency anemia was $25 \%$, and the total anemia prevalence was $32 \%$. Only $15 \%$ of children consumed iron-rich foods in the preceding 24 hours, and 30\% of children consumed iron-rich foods at least once in the preceding week. IDA decreased as the height for age z-score increased (Adjusted Odds Ratio 0.7; 95\% CI 0.5-0.9). Mothers with increased educational level (AOR 1.1; 1.0-1.2) and households with increased dietary diversity (AOR 1.4; 1.2-1.6) consumed more iron-rich foods. Conclusions: Iron deficiency anaemia was a moderate public health problem in southern Ethiopia, and the iron-rich food consumption was low. Interventions 
47 should focus on food supplementation and fortification, food diversification and nutritional

48 education and promoting women's education.

49 Key words: Iron deficiency anemia, serum ferritin adjustment, and iron-rich food consumption.

\section{Background}

One-fourth of the global population is affected by anemia and the highest prevalence is in preschool age children (World Health Organization, 2015). In Ethiopia, 56\% of the children under the age of five years were anemic (Central Statistical Agency, 2016). It has long been assumed that up to half of the cases of anemia are due to iron deficiency (World Health Organization, 2005). But the recent review found that iron deficiency accounts for 25 percent of anemia in young children and 37 percent of anemia in women of reproductive age. Moreover, significant variations exist between countries, which may render generalized assumptions misleading (Green et al., 2017).

Children are particularly vulnerable to iron-deficiency anemia because of their increased iron requirements during periods of rapid growth, especially in the first five years of life. In children, iron deficiency can affect cognitive and motor development and increase susceptibility to infections (Batra and Sood, 2005).

In developing countries diets are dominated by starchy cereals that are low in lipids, proteins, vitamins, and minerals including iron (Harika et al., 2017). Poor families, which constitute the majority of the population in Ethiopia as well as in other low-income countries, often cannot afford animal food products that have high amounts of easily absorbable iron (Gebreegziabiher et al., 2014, Kejo et al., 2018). In Ethiopia, iron-rich food consumption by 
children is less than $21 \%$ (Tiruneh et al., 2020, Herrador et al., 2015) and more than $70 \%$ of the children scored low on dietary diversity assessments (Temesgen et al., 2018, Worku et al., 2020).

The current public health policy is supporting efforts to reduce child malnutrition in general and child anemia in particular, by promoting dietary diversity, deworming, iron supplementation during pregnancy, and malaria prevention (Federal Democratic Republic of Ethiopia, 2018). Despite these efforts, the prevalence of anemia among children less than five years old increased from 44\% in 2011 to 57\% in 2016 (Central Statistical Agency, 2016).

Diagnosing iron deficiency anemia is challenging in the presence of acute or chronic inflammations (Grant et al., 2012). In Ethiopia studies of IDA are often restricted by a shortage of laboratory facilities, and because of challenges in interpretation of biomarkers for IDA due to high burden of infections (Namaste et al., 2017b). We assumed there would be a high prevalence of IDA among children in the study area due to the high burden of anemia, limited access to iron supplementation and fortified foods, and lack of iron in the foods (Central Statistical Agency, 2016). In Ethiopia, literature on IDA is not only limited but also inconsistent. Different studies reported varying prevalence rates. The Ethiopia National Micronutrient Survey in 2014 estimated $8.6 \%$ of IDA prevalence at the national level among children 6-59 months old (Ministry of Health, 2016), and a study from southwest Ethiopia reported $37 \%$ of IDA among school children (Desalegn et al., 2014). Hence, determining the prevalence of iron deficiency anemia is important to plan appropriate interventions and thereby to minimize future health risks (GarciaCasal et al., 2018). This study aimed to establish the prevalence of iron- deficiency anemia and associated risk factors, focusing on the assessment of iron-rich food consumption among children aged 2 to 5 years in southern Ethiopia. 


\section{Methods}

\section{Ethical consideration}

The institution's ethical board of Hawassa University (IRB/098/08) and the Regional Ethical Committee West Norway (No. 2016/2034) provided ethical approvals. Hawassa University College of Medicine and Health Sciences approved to undertake field work (No.1471/09). Local administrative and health authorities of Hawassa City Administration Hawella Tula sub city Health Office (No. 3214/09) also granted official permission. Informed written consent was obtained from mothers for all study participants.

\section{Study area}

This cross sectional study is a part of a larger study that aimed to evaluate the efficacy of home processed amaranth grain containing bread in the treatment of anemia among 2-5 year-old children in southern Ethiopia (Orsango et al., 2020). Thus, the Cheffe Cote Jebessa Kebele was purposively selected because amaranth grain grows as a wild crop in the village. The plant amaranth was used to prepare an alternative plant-based iron-rich food that is easily accessible and acceptable for children (Orsango et al., 2020, Zebdewos et al., 2015). The study area is located in a semi-urban part of Hawassa city in southern Nations Nationalities Peoples Regional state, $273 \mathrm{~km}$ south of Addis Ababa, the capital city of Ethiopia. The study was conducted from February 15, to March 30,2017. According to a census we conducted before the start of our study, the population of the village was 23010 people with 3900 households, and 1689 children aged 2-5 years old. Since it is a semi-urban area, some of the household members are farmers and some of them are engaged in non-agricultural activities in Hawassa city. The farmers cultivate maize, haricot beans, ensete, and Irish potatoes.

\section{Sampling procedure and sample size}


113

114 (Sullivan et al., 2009) considering the 33\% national average prevalence of anemia among

115 children aged 3-5 years old (Central Statistical Authority, 2012), 95\% confidence level, and 5\%

116

117

118

119

120

121

122

123

124

125

126

127

128

129

130

131

132

133

134

margin of error. From the census list, 340 children were randomly selected using SPSS random generation technique (Fig S1).

\section{Study Participants}

This cross-sectional study was done before the trial (Orsango et al., 2020), and we randomly selected 340 children aged 2 to 5 years and their mothers or caregivers, all of whom lived in the study area and who provided informed consent. We excluded children with conditions that precluded them from participating in measurements and venipuncture.

\section{Study variables}

The primary outcome variable of this study was iron deficiency anemia, and secondary outcome variable was iron-rich food consumption. Independent variables of the study were socio-demography factors, economic status, dietary intake, and nutritional conditions of children.

\section{Blood collection and laboratory methods}

Professional laboratory technicians have collected $3-5 \mathrm{ml}$ of blood specimens from the vein by using a lithium heparin plasma separator test tube that used to measure hemoglobin, serum ferritin, and CRP (Wei et al., 2010). Hemoglobin was determined immediately on-site using HemoCue analyzers 301(Sweden). All samples with hemoglobin levels $<11 \mathrm{~g} / \mathrm{dl}$ were tested further for serum ferritin and CRP concentration. For determination of serum ferritin level and CRP, the blood samples in the test tubes were immediately wrapped in aluminum foil, continuously shielded from light, and stored for 30 minutes at $4{ }^{\circ} \mathrm{C}$ until centrifugation. After 
135 centrifuging, serum was kept in plastic screw-capped tubes with the participant's identity and

136 stored at $-20^{\circ} \mathrm{C}$. Then the serum was transported in a cold box chain for analysis of ferritin and

137 CRP to the Ethiopian Public Health Institute at Addis Ababa.

$138 \mathrm{C}$ - reactive protein (CRP) was measured on Cobas 6000 (c501 module) Roche (Germany) by

139 applying enhanced immunoturbidimetric assay principle. Ferritin was measured on Cobas 6000

140 (e601 module) Roche (Germany) by applying electrochemiluminescence immunoassay (ECLIA)

141 specifically the sandwich principle. Ferritin results were determined by 2-point calibration and a

142 master curve provided via the reagent barcode.

\section{Biomarkers and definitions used to assess ferritin level}

144 IDA was evaluated based on hemoglobin, serum ferritin, and CRP concentration.

145 Hemoglobin concentrations were corrected for altitudes by subtracting $0.8 \mathrm{~g} / \mathrm{dl}$ per $500 \mathrm{~m}$ altitude

146 to get the estimated sea level value (Sullivan et al., 2008, World Health Organization, 2011a).

147 Anemia was defined as hemoglobin concentration adjusted for altitude less than $11 \mathrm{~g} / \mathrm{dl}$ and

148 classified as normal ( $\geq 11.0 \mathrm{~g} / \mathrm{dl})$, mild $(10.0-10.9 \mathrm{~g} / \mathrm{dl})$, moderate $(7.0-9.9 \mathrm{~g} / \mathrm{dl})$, and severe

$149(<7.0 \mathrm{~g} / \mathrm{dl})($ Sullivan et al., 2008).

150 Ferritin concentration was adjusted for inflammation using correction methods

151 recommended by WHO in 2020 (World Health Organization, 2020). First, the prevalence of low

152 ferritin $(<12 \mu \mathrm{g} / \mathrm{L})$ was calculated on the basis of unadjusted ferritin estimates. Subsequently, the

153 following three adjustment approaches were applied to account for inflammation under this

154 study:

155 - Exclusion approach: The exclusion approach excluded individuals with elevated CRP concentration $>5 \mathrm{mg} / \mathrm{L}$, and calculated the prevalence of low ferritin in the remaining individuals considering ferritin concentration cut-off $<12 \mu \mathrm{g} / \mathrm{L}$. 
158

159

160

161

162

163

164

165

166

167

168

169

170

171

172

173

174

175

176

177

178

179

- Higher ferritin cut-off: The higher ferritin cut-off adjustment approach uses a higher ferritin concentration cut-off $<30 \mu \mathrm{g} / \mathrm{L}$. There were two different approaches when the high ferritin cut-off was used. The cut-off applied for the entire sample as well as the subset of individuals with elevated CRP as defined by a CRP concentration $>5 \mathrm{mg} / \mathrm{L}$. For this study, we used cut-off for the subset of individuals with elevated CRP (World Health Organization, 2020).

- Internal correction factor: The correction factor $(\mathrm{CF})$ was calculated as the ratio of geometric means of the reference group (non-elevated CRP) to that of the respective inflammation groups (elevated CRP). We found a CF value equal to 0.85 (Thurnham et al., 2010, Namaste et al., 2017b, Namaste et al., 2017a). Then, to get the adjusted ferritin the subgroup with CRP $>5 \mathrm{mg}$ was multiplied by 0.85 (Gibson, 2005, World Health Organization, 2011b). Subsequently, low ferritin was defined $<12 \mu \mathrm{g} / \mathrm{L}$ for both groups of elevated CRP or not elevated CRP.

Finally, we used the higher ferritin cut-off adjustment approach because we got the higher prevalence of iron deficiency anaemia by this approach. Furthermore, we measured only CRP not have the data on AGP concentration and malaria, this could prevent us to rely completely on correction factor and the regression correction approach (World Health Organization, 2020). Iron deficiency anemia was defined as children having a combination of hemoglobin level of less than $11 \mathrm{~g} / \mathrm{dl}$ and adjusted low ferritin concentration $(<12 \mu \mathrm{g} / \mathrm{L})$ (World Health Organization (WHO), 2014, World Health Organization, 2011b).

\section{Anthropometric measurements}



taken using a Seca213 height board (Seca 213, Seca GmbH, Hamburg, Germany) with a sliding

182 headpiece while the child stood straight. Weight was taken using a calibrated Seca 874 electronic 183 flat scale (Seca 874, Seca GmbH, Hamburg, Germany) with the child barefoot and wearing light

184 clothing. Anthropometric measurements were calculated according to the Emergency Nutrition Assessment for SMART software 2011 (Toronto, Canada), developed using WHO child growth standards (Juergen et al., 2015). Weight and height measurements were converted to height-forage (HAZ), weight-for-age (WAZ), and weight-for-height (WHZ) z-scores, based on WHO reference standards. For WHZ, a z-score $<-2$ indicated wasting, $\geq-2$ to $<2$ indicated normal, and $>2$ indicated overweight. For HAZ, a z-scores $<-2$ indicated stunting, and $>-2$ indicated normal. WAZ $z$-scores $<-2$ indicated underweight and $>-2$ indicated normal. Moderate and severe undernutrition were defined as z-scores $<-2$ and $<-3$, respectively (WHO Multicentre Growth Reference Study Group, 2006).

\section{Dietary assessment}

A 24-hour dietary recall questionnaire and 7 days structured food-frequency questionnaires adapted to the local context from Food and Agriculture Organization (FAO) guidelines were used to collect information about dietary practices (Food and Agricultural Organization, 2010). The 24-hour and seven days child food frequency recall were computed in to nine food groups: cereals, roots and tubers; vitamin A-rich fruits and vegetables; other fruit; other vegetables; legumes and nuts; meat, poultry and fish; fats and oils; dairy; and eggs. Dietary diversity score calculated by summing the number of food groups based on FAO guidelines, with scores ranging from low ( $\leq 3$ food items), medium ( $4-5$ food items), and high ( $\geq 6$ food items). 
202

203

204

205

206

207

The 24 hour household dietary diversity was computed into twelve food groups: cereals, white tubers and roots, vegetables, fruits, meat, eggs, fish and other seafood, legumes, nuts and seeds, milk and milk products, oils and fats, sweets spices, condiments, and beverages (Food and Agricultural Organization, 2010). The Dietary Diversity score was based on the computation of the different food groups consumed and the volume (quantity) of food and nutrient intake were not measured.

The consumption of iron rich food was defined as if a child consumed at least one iron-rich food item among the following food groups: organ meat, flesh meat, or fish at any time in the last 24 hours or at least once in the last seven days preceding the interview.

The household food insecurity status was determined using the 9-component Household Food Insecurity Access Scale validated in Ethiopia (Gebreyesus et al., 2015). The HFIAS is composed of nine items, which are asked with a recall period of 1 month. For each item, there was a follow-up of the frequency of the occurrence question. Responses scored 'never' received a score of 0 , 'rarely' scored 1, 'sometimes' scored 2, and 'often' scored 3, so that when summed, the lowest possible score was 0 and the highest 27 . Household food security was categorized into four levels (food secure, mildly food insecure, moderately food insecure, and severely food insecure) based on the guidelines (Coates et al., 2007).

Furthermore, data on child morbidity (diarrhoea and cough for the last 15 days), child immunization, history of hospital admission, iron-fortified food consumption of children, and iron supplementation for the mother and child were collected.

\section{Socioeconomic status}



presence or absence of each household item was coded as ' 0 ' for No and ' 1 ' for Yes. Variables

225

226

227

228 included electricity access, as well as ownership of a radio, telephone, television, refrigerator, electric stove, bicycle, motorcycle, car, or computer. Ownership of land, domestic animals, household monthly income, and the number of people in the household, parent education, and occupation were excluded from the model. The first component explained most of the variance in the observed set of variables, and the final model explained $32 \%$ of the variance. We then created a wealth index using tertiles that were distributed into three groups: poor, medium, and richest (Beaumont, 2012).

\section{Statistical analysis}

Data were double-entered and checked using EpiData v.3.1 (EpiData.dk, Odense, Denmark) and transferred to IBM SPSS v.20 (SPSS Inc. Chicago, IL, USA) for analysis. Descriptive statistics were used to summarize categorical variables. Means with $95 \%$ confidence intervals (CI), medians, and interquartile range were used to present continuous variables. The bi-variable analysis was done to check the association between each independent variable with the IDA and iron-rich food consumption. All variables with P-value $<0.3$ were included in the multivariable logistic regression analysis to retain some potential confounding variables. Variables with a P-value less than 0.05 were considered statistically significant. Factors associated with consumption of iron-rich food at least once in the last seven days were determined. Multicollinearity among independent variables was checked and the variables with tolerance test $<0.2$ and variance inflation factor $(\mathrm{VIF})>5.0$ were excluded from the models.

The conceptual modelling approach published by Victora et.al was adopted to develop for this specific study which used to determine factors associated with iron deficiency anemia 
246 (Victora et al., 1997). In the multivariable analysis factors associated with IDA were determined

247 using three-level regression analyses (level one underlying factors, level two intermediate

248 factors, and level three immediate factors). Figure two described variables in the conceptual

249 modelling developed for this study (Fig S2).

250

251

252

253

254

255

256

257

258

259

260

261

262

263

264

265

266

267

\section{Data quality and control}

To assure the quality of the data generated, standard operating procedures were followed during blood sample collection and all laboratory procedures. Structured questionnaires were translated into the local Sidamo and Amharic languages. A two-day intensive training was given for data collectors and supervisors regarding study objective, questionnaire, interview techniques, anthropometric measurements, blood sample collection, and ethical issues during data collection. A pre-test was done among 17 mother-child-pairs in the nearest village outside of the study area before the actual study. The data collection was checked daily for accuracy, consistency, and completeness by the supervisor. Anthropometry and hemoglobin instruments were calibrated as per standards.

\section{Results}

\section{Child characteristics}

From the sampled 340 children, 331 participated in the survey ( $97.4 \%$ response rate). Of the 331 children, $172(52 \%)$ were girls, and the mean age was 39.2 (95\% CI: $38.1-40.6)$ months. From the total of 331 children, only $10(3 \%)$ children had received iron supplementation, and two of them were diagnosed with anemia and one was diagnosed with iron deficiency anemia.

The children's illness history indicated that in the last two weeks preceding the survey, 100 $(30 \%)$ children had watery diarrhea, and $71(21 \%)$ had a cough. The nutritional status of children 
268 indicated that $125(37 \%)$ children were stunted, $4(1.3 \%)$ were wasted, and $72(21 \%)$ were

269 underweight (Table 1).

270 Socio-demographic characteristics of mothers and households

271 A total of 331 mothers participated in the survey and their mean age was 27.7 years $(95 \%$

272 CI: 27.1-28.3). The majority of mothers 231 (70\%) were women working at home, $75(22 \%)$ had 273 no formal education, and 207 (62\%) households were food insecure (Table 2).

\section{Iron rich food consumption}

The 24-hours child dietary recall indicated that the mean dietary diversity was $2.8(95 \%$ CI: 2.6-3.0) and the median was 3 (IQR 2-4, range 0-8). Most of the children 242 (73\%) scored low on dietary diversity (Table 1), only 50 (15\%) children had consumed iron-rich food (meat, organ meat, and fish). The diet of the children contained mostly starchy staples 326 (98.6\%). The seven days food frequency data showed that 104 (33\%) children consumed iron-rich food at least once within the last seven days (Table 3). Furthermore, household iron-rich food intake was similar to child iron intake of the last 24 hours, it showed that only $51(15 \%)$ of the household consumed iron-rich food (Fig 1).

\section{Magnitude of anemia and inflammation}

The mean hemoglobin concentration of the children was $11.6 \mathrm{~g} / \mathrm{dl}$ (95\% CI: 11.5-11.7), and the median was $11.8 \mathrm{~g} / \mathrm{dl}$ (IQR: 10.9-12.5). The prevalence of anemia was 107/331 (32.3\%). Of the total number of anemic children, only $1(0.9 \%)$ child had severe anemia, $35(32.7 \%)$ had moderate, and 71 (66.4\%) had mild anemia. The CRP measurements indicated that 23/107 (21 \%) of anemic children had some sort of inflammation (Table 4).

\section{Iron Deficiency anemia (IDA)}


The estimated prevalence rates of IDA varied when using different adjustment methods. It

291

292

293 was low in the unadjusted ferritin for inflammation group (18.7\%) and, its prevalence ranged from $22 \%$ with the exclusion approach, $23 \%$ with correction factor approach and $25 \%$ with adjustment methods (Table 5).

\section{Factors associated with iron deficiency anemia (IDA)}

Using higher ferritin cut-off adjustment approach we estimated the Odds Ratios for IDA. The adjusted odds ratio showed that the prevalence of IDA significantly decreased as the height for age z-score increased (AOR 0.7; 0.5-0.9) (Table 6).

\section{Factor associated with iron-rich food consumption}

Iron-rich food consumption at least one time in the last seven days indicated that mother's education (AOR 1.1; 1.0-1.2) and high household dietary diversity (AOR 1.4; 1.2-1.6) were positively associated with child iron-rich food consumption (Table S3).

\section{Discussion}

This study has revealed that one-fourth of the anemia cases were due to IDA, and the 24 hours food frequency recall showed that only $15 \%$ of children consumed iron-rich food and $30 \%$ of children consumed iron-rich food at least once in the last week preceding the survey. These findings are comparable with $20 \%$ of iron-rich food consumption by children less than five years of age within the last 24 hours reported in Ethiopia (Tiruneh et al., 2020). Iron deficiency anemia was associated with a low height for age of the children, while low iron-rich food consumption was associated with mother's education and household dietary diversity score. In our study, the prevalence of anemia was $32 \%$,which is comparable with the prevalence studies in northern Ethiopia for children in the 6-59 months age group (Gebreegziabiher et al., 2014). 
The $25 \%$ prevalence of iron deficiency anemia in our study was higher than the Ethiopian

313 National Micronutrient Survey which estimated a 9\% prevalence of iron deficiency anemia

314 among pre-school children in 2016. To our knowledge, there are no earlier community based

315 studies done in Ethiopia on iron deficiency anemia among young children, however, a study

316 from south-western Ethiopia in school children reported a higher prevalence of $37 \%$ of iron-

317 deficiency (Desalegn et al., 2014). The discrepancy may be due to age differences and because

318 the socio-economic and dietary practices could vary across the regions. Studies from Rwanda

319 showed a similar result with our findings in the age range 6-59 months (Rutayisire et al., 2019 ),

320 whereas in Angola 46\% of anemia cases were because of iron deficiency in children 3-36 months

321 of age (Fancony et al., 2020). Furthermore, a recent review finding indicated that $25 \%$ of anemia

322 in young children was because of iron deficiency (Green et al., 2017).

We used different inflammation adjustment methods under this study to estimate IDA and we found some variation of the prevalence among these different methods (World Health Organization, 2020, Namaste et al., 2017b, Thurnham et al., 2010). The variation of proportion of iron deficiency anemia with inflammation adjustment could be explained by the high burden of inflammation among children in the study area (Engle-Stone et al., 2017, Merrill et al., 2017). Furthermore, the study shows that inflammation is one of the causes of iron deficiency anemia

329 (Fancony et al., 2020). This could be because iron deficiency may lead to delayed growth and development in children. 
In our study iron deficiency anemia was not associated with iron-rich food consumption,

336

337

338

339

340

341

342

343

344

345

346

347

348

349

350

351

352

353

354

355

356

however iron-rich food consumption was associated with demographic and socio-economic characteristics of the households. Nevertheless, the lack of association with IDA must be interpreted with care as only 107 cases were involved, and the study may not have been sufficiently powered to detect all risk factors statistically. However, studies from Rwanda and Brazil have also show that socio-demographic characteristics of the household were not associated with iron deficiency anemia (Nobre et al., 2017, Rutayisire et al., 2019). In this study, mothers with better education ate more iron-rich foods, as it is supported by other studies in Ethiopia (Tiruneh et al., 2020, Choi et al., 2011).

\section{Strength and limitation of the study}

One of the strengths of this study is that it represents one of the few studies in Ethiopia that has assessed iron deficiency anemia using a representative sample of a community. The study was done in a farming community, and was a part of a larger study that aimed to evaluate the efficacy of home processed amaranth grain containing bread in the treatment of anemia among two-to-five year-old children in southern Ethiopia (Orsango et al., 2020). Even if the area represents a semi-urban part of a town, many of the household members practice agriculture typical of many areas in southern Ethiopia. Furthermore, iron deficiency anemia was assessed based on ferritin concentration adjusted for inflammation. A limitation of the study was that we did not assess potential causes of other types of anemia that could be prevalent in the area. Our sample size calculation was based on the EDHS 2011 report since our proposal development and approval was done before the release of 2016 EDHS report. Also children aged 3-5 years of age were used for sample calculation as EDHS were not reporting on the age group 2-5 years of age. Moreover, it was not possible to know the cause-effect relationship of the factors as it was a 
358 cross-sectional study. We used higher ferritin cut-off adjustment approach. Using a higher

359 ferritin-concentration cut-off value for individuals with infection/inflammation $<30 \mu \mathrm{g} / \mathrm{L}$ was

360 preferred to give a conclusion in our study. Because we didn't have the data on AGP

361 concentration and malaria, results have to rely completely on the arithmetic correction factor

362 approach and the regression correction approach.

\section{Conclusion}

This study found that one-third of the children were anemic, and one fourth of the anemic children had iron deficiency anemia among children 2-5years of age in a semi-urban area of southern Ethiopia. Furthermore, the consumption of iron rich food by children was low, and iron deficiency anemia was linked to low height for age measures. Based on the WHO classification, IDA was a moderate public health problem among our study participants. Thus, both short and long term interventions should be implemented to mitigate the adverse effect of iron deficiency anemia in the study area. Short-term solutions could include food supplementation and fortification strategies, and long-term intervention should focus on improving food diversification, nutritional education, and promoting women's education. Furthermore, emphases should be given to reduce high burden of inflammation in the study area. We recommend further studies on area specific iron deficiency anemia to include AGP and malaria status to see any variation in the prevalence of IDA and study on potential causes of other types of anemia that

376 could be prevalent in the area.

\section{References}

BATRA, J. \& SOOD, A. 2005. Iron deficiency anaemia: Effect on congnitive development in children: A review. Indian J Clin Biochem, 20 (2), 119-125. 
BEAUMONT, R. 2012. An introduction to Principal Component Analysis \& Factor Analysis Using SPSS 19 and R (psych package).

CENTRAL STATISTICAL AGENCY 2016. Ethiopia Demographic and Health Survey 2016. Addis Ababa, Ethiopia and Maryland, USA: CSA and ICF.

CENTRAL STATISTICAL AUTHORITY 2012. Ethiopia Demographic and Health Survey 2011. Addis Ababa, Ethiopia and Calverton, Maryland, USA: Central Statistical Agency and ICF International.

CHOI, H.-J., LEE, H.-J., JANG, H., PARK, J., KANG, J.-H., PARK, K. H. \& SONG, J. 2011. Effects of maternal education on diet, anemia, and iron deficiency in Korean school-aged children. BMC public health, 11, 870 .

COATES, J., ANNE, S. \& PAULA, B. 2007. Household Food Insecurity Access Scale (HFIAS) for measurement of household food access: Indicator Guide (V.3) Washington, D.C.: Food and Nutrition Technical Assistance Project, Academy for Educational Development (FANTA).

DESALEGN, W., MOSSIE, A. \& GEDEFAW, L. 2014. Nutritional iron deficiency anemia: magnitude and its predictors among school age children, southwest Ethiopia: a community based cross-sectional study. PLoS One, 9, e114059.

ENGLE-STONE, R., AARON, G. J., HUANG, J., WIRTH, J. P., NAMASTE, S. M., WILLIAMS, A. M., PEERSON, J. M., ROHNER, F., VARADHAN, R., ADDO, O. Y., TEMPLE, V., RAYCO-SOLON, P., MACDONALD, B. \& SUCHDEV, P. S. 2017. Predictors of anemia in preschool children: Biomarkers Reflecting Inflammation and Nutritional Determinants of Anemia (BRINDA) project. Am J Clin Nutr, 106, 402s-415s.

FANCONY, C., SOARES, A., LAVINHA, J., BARROS, H. \& BRITO, M. 2020. Iron deficiency anaemia among 6-to-36-month children from northern Angola. BMC Pediatr, 20, 298.

FEDERAL DEMOCRATIC REPUBLIC OF ETHIOPIA 2018. Seqota Declaration Innovation Phase Investment Plan 2017 - 2020

FOOD AND AGRICULTURAL ORGANIZATION 2010. Guidelines for measuring household and individual dietary diversity Nutrition and Consumer Protection Division, Food and Agriculture Organization of the United Nations.

GARCIA-CASAL, M. N., PENA-ROSAS, J. P., URRECHAGA, E., ESCANERO, J. F., HUO, J., MARTINEZ, R. X. \& LOPEZ-PEREZ, L. 2018. Performance and comparability of laboratory methods for measuring ferritin concentrations in human serum or plasma: A systematic review and meta-analysis. PLoS One, 13, e0196576.

GEBREEGZIABIHER, G., ETANA, B. \& NIGGUSIE, D. 2014. Determinants of Anemia among Children Aged 6-59 Months Living in Kilte Awulaelo Woreda, Northern Ethiopia. Anemia, 2014, 245870.

GEBREYESUS, S. H., LUNDE, T., MARIAM, D. H., TASEW, W. \& LINDTJØRN, B. 2015. Is the adapted household food insecurity access scale (HFIAS) developed internationally to measure food insecurity valid in urban and rural households of Ethiopia? BMC Nutrition $1,2$.

GIBSON, R. S. 2005. Principles of Nutrtional Assessment New York, Oxford University Press,Inc.

GRANT, F. K. E., SUCHDEV, P. S., FLORES-AYALA, R., COLE, C. R., RAMAKRISHNAN, U., RUTH, L. J. \& MARTORELL, R. 2012. Correcting for inflammation changes 
estimates of iron deficiency among rural Kenyan preschool children. The Journal of nutrition, 142, 105-111.

GREEN, T., KARAKOCHUK, C., DARY, O., ENGLE-STONE, R. \& NAMASTE, S. 2017. New Findings on Iron Deficiency Anemia: Experts Weigh In.

HABIB, M. A., BLACK, K., SOOFI, S. B., HUSSAIN, I., BHATTI, Z., BHUTTA, Z. A. \& RAYNES-GREENOW, C. 2016. Prevalence and Predictors of Iron Deficiency Anemia in Children under Five Years of Age in Pakistan, A Secondary Analysis of National Nutrition Survey Data 2011-2012. PLoS One, 11, e0155051.

HARIKA, R., FABER, M., SAMUEL, F., KIMIYWE, J., MULUGETA, A. \& EILANDER, A. 2017. Micronutrient Status and Dietary Intake of Iron, Vitamin A, Iodine, Folate and Zinc in Women of Reproductive Age and Pregnant Women in Ethiopia, Kenya, Nigeria and South Africa: A Systematic Review of Data from 2005 to 2015. Nutrients, 9.

HERRADOR, Z., PEREZ-FORMIGO, J., SORDO, L., GADISA, E., MORENO, J., BENITO, A., ASEFFA, A. \& CUSTODIO, E. 2015. Low Dietary Diversity and Intake of Animal Source Foods among School Aged Children in Libo Kemkem and Fogera Districts, Ethiopia. PloS one, 10, e0133435-e0133435.

JUERGEN, E., GOLDEN MICHAEL \& SEAMAN JHON. 2015. Software for Emergency Nutrition Assessment (ENA for SMART). SMART 2011.

KEJO, D., PETRUCKA, P. M., MARTIN, H., KIMANYA, M. E. \& MOSHA, T. C. 2018. Prevalence and predictors of anemia among children under 5 years of age in Arusha District, Tanzania. Pediatric Health Med Ther, 9, 9-15.

MERRILL, R. D., BURKE, R. M., NORTHROP-CLEWES, C. A., RAYCO-SOLON, P., FLORES-AYALA, R., NAMASTE, S. M., SERDULA, M. K. \& SUCHDEV, P. S. 2017. Factors associated with inflammation in preschool children and women of reproductive age: Biomarkers Reflecting Inflammation and Nutritional Determinants of Anemia (BRINDA) project. Am J Clin Nutr, 106, 348s-358s.

MINISTRY OF HEALTH 2016. Ethiopian Public Health institute Ethiopian National micronutrient survey report

NAMASTE, S. M., AARON, G. J., VARADHAN, R., PEERSON, J. M. \& SUCHDEV, P. S. 2017a. Methodologic approach for the Biomarkers Reflecting Inflammation and Nutritional Determinants of Anemia (BRINDA) project. Am J Clin Nutr, 106, 333s-347s.

NAMASTE, S. M., ROHNER, F., HUANG, J., BHUSHAN, N. L., FLORES-AYALA, R., KUPKA, R., MEI, Z., RAWAT, R., WILLIAMS, A. M., RAITEN, D. J., NORTHROPCLEWES, C. A. \& SUCHDEV, P. S. 2017b. Adjusting ferritin concentrations for inflammation: Biomarkers Reflecting Inflammation and Nutritional Determinants of Anemia (BRINDA) project. The American journal of clinical nutrition, 106, 359S-371S.

NOBRE, L. N., LESSA, A. D. C., OLIVEIRA, H. C. D., LAMOUNIER, J. A. \& FRANCISCHINI, S. D. C. C. 2017. Iron-deficiency anemia and associated factors among preschool children in Diamantina, Minas Gerais, Brazil. Revista de Nutrição, 30, 185196.

ORSANGO, A. Z., LOHA, E., LINDTJØRN, B. \& ENGEBRETSEN, I. M. S. 2020. Efficacy of processed amaranth-containing bread compared to maize bread on hemoglobin, anemia and iron deficiency anemia prevalence among two-to-five year-old anemic children in Southern Ethiopia: A cluster randomized controlled trial. PLoS One, 15, e0239192. 
RUTAYISIRE, E., NWAIKE, S. O. \& MARETE, O. 2019. Prevalence of Iron Deficiency Anaemia and Associated Factors among Children Aged Six to Fifty Nine Months Seen at Kabutare District Hospital, Rwanda. EC Nutrition, 14, 01-12.

RUTAYISIRE, E., NWAIKE, S. O. \& MARETE, O. 2019 Prevalence of Iron Deficiency Anaemia and Associated Factors among Children Aged Six to Fifty Nine Months Seen at Kabutare District Hospital, Rwanda. EC Nutrition 14.12, 01-12.

SOLIMAN, A. T., AL DABBAGH, M. M., HABBOUB, A. H., ADEL, A., HUMAIDY, N. A. \& ABUSHAHIN, A. 2009. Linear growth in children with iron deficiency anemia before and after treatment. $J$ Trop Pediatr, 55, 324-7.

SULLIVAN, K. M., DEAN, A. \& SOE, M. M. 2009. OpenEpi: a web-based epidemiologic and statistical calculator for public health. Public health reports (Washington, D.C. : 1974), 124, 471-474.

SULLIVAN, K. M., MEI, Z., GRUMMER, S. L. \& PARVANTA, I. 2008. Haemoglobin adjustments to define anaemia. Trop Med Int Health, 13, 1267-71.

TEMESGEN, H., NEGESSE, A., WOYRAW, W. \& MEKONNEN, N. 2018. Dietary diversity feeding practice and its associated factors among children age 6-23 months in Ethiopia from 2011 up to 2018: a systematic review and meta-analysis. Italian journal of pediatrics, 44, 109-109.

THURNHAM, D. I., MCCABE, L. D., HALDAR, S., WIERINGA, F. T., NORTHROPCLEWES, C. A. \& MCCABE, G. P. 2010. Adjusting plasma ferritin concentrations to remove the effects of subclinical inflammation in the assessment of iron deficiency: a meta-analysis. Am J Clin Nutr, 92, 546-55.

TIRUNEH, S. A., AYELE, B. A., YITBAREK, G. Y., ASNAKEW, D. T., ENGIDAW, M. T. \& GEBREMARIAM, A. D. 2020. Spatial distribution of iron rich foods consumption and its associated factors among children aged 6-23 months in Ethiopia: spatial and multilevel analysis of 2016 Ethiopian demographic and health survey. Nutrition journal, 19, 115.

VICTORA, C. G., HUTTLY, S. R., FUCHS, S. C. \& OLINTO, M. T. 1997. The role of conceptual frameworks in epidemiological analysis: a hierarchical approach. Int $J$ Epidemiol, 26, 224-7.

WEI, Y.-H., ZHANG, C.-B., YANG, X.-W. \& JI, M.-D. 2010. The Feasibility of Using LithiumHeparin Plasma From a Gel Separator Tube as a Substitute for Serum in Clinical Biochemical Tests. Laboratory Medicine, 41, 215-219.

WHO MULTICENTRE GROWTH REFERENCE STUDY GROUP 2006. WHO child growth standards based on length/height, weight and age. Acta Pcedi 450, 76-85.

WORKU, T., GONETE, K. A., MUHAMMAD, E. A. \& ATNAFU, A. 2020. Sustainable under nutrition reduction program and dietary diversity among children's aged 6-23 months, Northwest Ethiopia: Comparative cross-sectional study. Int J Equity Health, 19, 14.

WORLD HEALTH ORGANIZATION 2005. Worldwide prevalence of anaemia 1993-2005 WHO Global Database on Anaemia. In: BENOIST, B. D., MCLEAN, E., EGLI, I. \& COGSWELL, M. (eds.). World Health Organization.

WORLD HEALTH ORGANIZATION 2011a. Haemoglobin concentrations for the diagnosis of anaemia and assessment of severity. Vitamin and Mineral Nutrition Information System Geneva: World Health Organization (WHO/NMH/NHD/MNM/11.1).

WORLD HEALTH ORGANIZATION 2011b. Serum ferritin concentrations for the assessment of iron status and iron deficiency in populations vitamin and mineral nutrition information system Geneva: WHO/NMH/NHD/MNM. 
WORLD HEALTH ORGANIZATION 2015. The Global Prevalence of Anaemia In 2011. Geneva: World Health Organization.

WORLD HEALTH ORGANIZATION 2020. Who Guideline On Use Of Ferritin Concentrations To Assess Iron Status In Individuals And Populations. In: ORGANIZATION, W. H. (ed.). Geneva.

WORLD HEALTH ORGANIZATION (WHO) 2014. C-reactive protein concentrations as a marker of inflammation or infection for interpreting biomarkers of micronutrient status vitamin and mineral nutrition information system. Geneva WHO/NMH/NHD/EPG.

ZEBDEWOS, A., SINGH P, BIRHANU G, WHITING SJ, HENRY CJ \& A KEBEBU 2015. Formulation of complementary food using amaranth, chickpea and maize improves iron, calcium and zinc content. ajfand, 15(1). 


\section{Table 1 (on next page)}

Demography, morbidity, and nutritional status of children aged 24-59 months in Cheffe Cote Jebessa kebele, southern Ethiopia, 2017 


\begin{tabular}{llrr}
\hline Variables & Characteristics & $\begin{array}{r}\text { Frequency } \\
\text { N=331 }\end{array}$ & Percent \\
\hline Child sex & & & \\
& Male & 159 & 48.0 \\
& Female & 172 & 52.0
\end{tabular}

Child age in months

$\begin{array}{lll}24-36 & 145 & 43.8 \\ 37-59 & 186 & 56.2\end{array}$

Mother response immunization completed

$\begin{array}{lrr}\text { No } & 25 & 7.6 \\ \text { Yes } & 306 & 92.4\end{array}$

Immunization completed

confirmed in child health card

$\begin{array}{lrr}\text { No } & 28 & 8.5 \\ \text { Yes } & 207 & 62.5 \\ \text { No card } & 96 & 29.0\end{array}$

Cough lasting 15 days

$\begin{array}{lrr}\text { No } & 260 & 78.5 \\ \text { Yes } & 71 & 21.5\end{array}$

Diarrhoea lasting 15 days

$\begin{array}{lll}\text { No } & 231 & 69.8 \\ \text { Yes } & 100 & 30.2\end{array}$

History of hospital admission

$\begin{array}{lrr}\text { No } & 289 & 87.3 \\ \text { Yes } & 41 & 12.4 \\ \text { Missing } & 1 & 0.3\end{array}$

Iron-rich food within last 24 hours

$\begin{array}{lrr}\text { No } & 281 & 84.9 \\ \text { Yes } & 50 & 15.1\end{array}$

Iron supplementation

$\begin{array}{lrr}\text { No } & 321 & 97.0 \\ \text { Yes } & 10 & 3.0\end{array}$

Iron-fortified food

$\begin{array}{lrr}\text { No } & 316 & 95.5 \\ \text { Yes } & 15 & 4.5\end{array}$

Child dietary diversity score

$\begin{array}{lrr}\text { Low } & 242 & 73.1 \\ \text { Medium } & 65 & 19.6 \\ \text { High } & 24 & 7.3\end{array}$




\section{Current breast feeding}

$\begin{array}{crr}\text { No } & 229 & 69.2 \\ \text { Yes } & 101 & 30.5 \\ \text { Missing } & 1 & 0.3\end{array}$

\section{Height-for-age score}

$\begin{array}{lll}\text { Stunting } & 125 & 37.8 \\ \text { Normal } & 206 & 62.2\end{array}$

\section{Weight-for-height score}

$\begin{array}{lrr}\text { Wasting } & 4 & 1.2 \\ \text { Normal } & 304 & 91.8 \\ \text { Overweight } & 9 & 2.7 \\ \text { Missing } & 14 & 4.2\end{array}$

Weight for age score

$\begin{array}{lrr}\text { Underweight } & 72 & 21.8 \\ \text { Normal } & 259 & 78.2\end{array}$

Missing value observed under the variable weight for height score was not the actual missing but the result flagged with WHO reference using ENASMART software. 


\section{Table 2 (on next page)}

Demographic and socio-economic characteristics of mothers and households, in Cheffe Cote Jebessa kebele, southern Ethiopia, 2017 


\begin{tabular}{clrr}
\hline Variables & \multicolumn{1}{c}{ Characteristics } & $\begin{array}{c}\text { Frequency } \\
\mathbf{N = 3 3 1}\end{array}$ & Percent \\
\hline Mothers' age in years & & & \\
& $<25$ & 135 & 40.8 \\
& $25-30$ & 133 & 40.2 \\
& $>30$ & 63 & 19.0
\end{tabular}

Mother's education

$\begin{array}{lrr}\text { No formal education } & 75 & 22.7 \\ 1-8 \text { school years } & 180 & 54.4 \\ >8 \text { school years } & 76 & 23.0\end{array}$

Father's education

$\begin{array}{lrr}\text { No formal education } & 47 & 14.3 \\ 1-8 \text { school years } & 168 & 51.2 \\ >8 \text { school years } & 113 & 34.5\end{array}$

\section{Mother's occupation}

$\begin{array}{lll}\text { Housewife } & 231 & 69.8 \\ \text { Employed } & 100 & 30.2\end{array}$

Number of people in household

$\begin{array}{lrr}<5 \text { people } & 222 & 67.1 \\ >5 \text { people } & 109 & 32.9 \\ & & \\ \text { Low } & 196 & 59.2 \\ \text { Medium } & 117 & 35.3 \\ \text { High } & 18 & 5.4\end{array}$

\section{Land ownership}

$\begin{array}{lll}\text { No } & 188 & 56.8 \\ \text { Yes } & 143 & 43.2\end{array}$

\section{Livestock ownership}

$\begin{array}{lll}\text { No } & 188 & 56.8 \\ \text { Yes } & 143 & 43.2\end{array}$

Wealth index

$\begin{array}{lrr}\text { Poor } & 126 & 38.1 \\ \text { Medium } & 82 & 24.8 \\ \text { Rich } & 123 & 37.2\end{array}$

Household food insecurity 
Moderate

Severe
72

103
21.8

31.1

1 


\section{Table 3 (on next page)}

Twenty-four hour's dietary recall and seven days food frequency recall 


\begin{tabular}{|c|c|c|c|c|c|c|}
\hline Food group & $\begin{array}{r}\text { 24-hour } \\
\text { recall }\end{array}$ & $\begin{array}{r}\text { Frequenc } \\
\mathbf{y} \\
(\mathrm{N}=331) \\
\end{array}$ & $\begin{array}{r}\text { Percen } \\
\mathbf{t}\end{array}$ & $\begin{array}{r}1 \text { week-frequency } \\
\text { recall }\end{array}$ & $\begin{array}{r}\text { Frequenc } \\
\mathbf{y} \\
(\mathbf{N}=331)\end{array}$ & $\begin{array}{r}\text { Percen } \\
t\end{array}$ \\
\hline \multirow[t]{4}{*}{ Starchy stable } & No & 5 & 1.5 & No intake & 2 & 0.6 \\
\hline & Yes & 326 & 98.5 & Once & 32 & 9.7 \\
\hline & & & & 2-4 times & 108 & 32.6 \\
\hline & & & & $>=5$ times & 189 & 57.1 \\
\hline \multirow{4}{*}{$\begin{array}{l}\text { Dark green } \\
\text { vegetables }\end{array}$} & No & 215 & 65.0 & No intake & 101 & 30.5 \\
\hline & Yes & 115 & 34.7 & Once & 49 & 14.8 \\
\hline & & & & 2-4 times & 145 & 43.8 \\
\hline & & & & $>=5$ times & 36 & 10.9 \\
\hline \multirow{4}{*}{$\begin{array}{l}\text { Vitamin A rich } \\
\text { fruit and vegetables }\end{array}$} & No & 231 & 69.8 & No intake & 90 & 27.2 \\
\hline & Yes & 100 & 30.2 & Once & 36 & 10.9 \\
\hline & & & & 2-4 times & 120 & 36.3 \\
\hline & & & & $>=5$ times & 85 & 25.7 \\
\hline \multirow{4}{*}{$\begin{array}{l}\text { Fruit and } \\
\text { vegetables recode }\end{array}$} & No & 230 & 69.5 & No intake & 289 & 87.3 \\
\hline & Yes & 101 & 30.5 & Once & 25 & 7.6 \\
\hline & & & & 2-4 times & 14 & 4.2 \\
\hline & & & & $>=5$ times & 3 & 0.9 \\
\hline \multirow[t]{2}{*}{ Organ meat } & No & 330 & 99.7 & No intake & 326 & 98.5 \\
\hline & Yes & 1 & 0.3 & Once & 5 & 1.5 \\
\hline \multirow[t]{4}{*}{ Meat and fish } & No & 281 & 84.9 & No intake & 227 & 68.6 \\
\hline & Yes & 49 & 14.8 & Once & 62 & 18.7 \\
\hline & & & & 2-4 per week & 37 & 11.2 \\
\hline & & & & $>=5$ times & 5 & 1.5 \\
\hline \multirow[t]{4}{*}{ Egg } & No & 302 & 91.2 & No intake & 239 & 72.2 \\
\hline & Yes & 29 & 8.8 & Once & 33 & 10 \\
\hline & & & & 2-4 times & 54 & 16.3 \\
\hline & & & & $>=5$ times & 5 & 1.5 \\
\hline \multirow[t]{4}{*}{ Legume and nuts } & No & 216 & 65.3 & No intake & 149 & 45 \\
\hline & Yes & 115 & 34.7 & Once & 46 & 13.9 \\
\hline & & & & 2-4 times & 99 & 29.9 \\
\hline & & & & $>=5$ times & 36 & 10.9 \\
\hline \multirow{4}{*}{$\begin{array}{l}\text { Milk and milk } \\
\text { products }\end{array}$} & No & 236 & 71.3 & No intake & 149 & 45 \\
\hline & Yes & 95 & 28.7 & Once & 35 & 10.6 \\
\hline & & & & 2-4 times & 94 & 28.4 \\
\hline & & & & $>=5$ times & 53 & 16 \\
\hline
\end{tabular}


Table 4 (on next page)

Magnitude of anemia and inflammation among children aged 2-5 years in Cheffe Cote Jebessa kebele, southern Ethiopia 


\begin{tabular}{llrr}
\hline Variables & Characteristics & Frequency & Percent \\
\hline \multirow{2}{*}{ Anemia N=107/331 } & Severe & 1 & 0.9 \\
& Moderate & 35 & 32.7 \\
Inflammation $\mathrm{N}=107$ & Mild & 71 & 66.4 \\
& & & 78.5 \\
& No $(\mathrm{CRP}<5 \mathrm{mg} / \mathrm{L})$ & 84 & 21.5 \\
\hline
\end{tabular}

1 


\section{Table 5 (on next page)}

Median (IQR) of ferritin level and prevalence of iron deficiency anemia given different adjustment methods

Note: Cl: confidence interval; IQR: inter quantile range; $\mu \mathrm{g} / \mathrm{L}$ : Micrograms per Litre 


\begin{tabular}{lccc}
\hline Correction method & Median (IQR) & \multicolumn{2}{c}{ Iron deficiency anemia n (\%) } \\
$\mathbf{N = 1 0 7}$ & Ferritin $(\boldsymbol{\mu g} / \mathbf{L})$ & No & Yes \\
\hline Ferritin not adjusted & $25.7(25.7-59.6)$ & $87(81.3)$ & $20(18.7)$ \\
Exclusion approach & $25.2(12.8-35.3)$ & $65(77.4)$ & $19(22.6)$ \\
Correction Factor approach & $24.5(12.6-34.6)$ & $82(76.6)$ & $25(23.4)$ \\
Higher ferritin-cut-off adjustment & $25.7(25.7-59.6)$ & $80(74.8)$ & $27(25.2)$
\end{tabular}

1 


\section{Table 6(on next page)}

Factors associated with iron deficiency anemia among children age 2-5 years in Cheffe Cote Jebessa kebele, southern Ethiopia, 2017

Note: Variables with a P-value $<0.3$ were included in multi-variable analysis. Bold format $\mathrm{p} \leq 0.05 ; \mathrm{Cl}$ : confidence interval; OR: odds ratio 


\begin{tabular}{|c|c|c|c|c|c|}
\hline \multirow{2}{*}{$\mathrm{N}=\mathbf{1 0 7}$} & & \multicolumn{2}{|c|}{ Iron deficiency anemia } & \multirow{2}{*}{$\begin{array}{r}\text { Crude OR } \\
(95 \% \text { CI })\end{array}$} & \multirow{2}{*}{$\begin{array}{r}\text { Adjusted OR } \\
(95 \% \mathrm{CI})\end{array}$} \\
\hline & & No $(\%)$ & Yes $(\%)$ & & \\
\hline \multicolumn{6}{|l|}{ Inherent factors } \\
\hline Age (continuous) & & & & $1.02(0.98-1.06)$ & $0.96(0.91-1.03)$ \\
\hline \multirow[t]{2}{*}{ Child sex } & Male & $29(36.3)$ & $12(44.4)$ & 1 & 1 \\
\hline & Female & $51(63.8)$ & $15(55.6)$ & $1.07(0.47-2.47)$ & $0.91(0.32-2.57)$ \\
\hline \multicolumn{6}{|l|}{ Underlying factors } \\
\hline \multirow[t]{2}{*}{ Land ownership } & No & $55(68.8)$ & $14(51.9)$ & 1 & 1 \\
\hline & Yes & $25(31.3)$ & $13(48.1)$ & $1.59(0.69-3.67)$ & $1.91(0.69-5.30)$ \\
\hline \multicolumn{6}{|l|}{ Intermediate factors } \\
\hline \multirow[t]{2}{*}{ Household food security } & $\begin{array}{l}\text { Food } \\
\text { insecure }\end{array}$ & $55(68.8)$ & $18(66.7)$ & 1 & 1 \\
\hline & $\begin{array}{l}\text { Food } \\
\text { secured }\end{array}$ & $25(31.3)$ & $9(33.3)$ & $0.97(0.41-2.33)$ & $0.76(0.25-2.28)$ \\
\hline $\begin{array}{l}\text { Height for age (HAZ) } \\
\text { (continuous) }\end{array}$ & & & & $0.86(0.73-1.00)$ & $0.74(0.56-0.98)$ \\
\hline $\begin{array}{l}\text { Weight for height (WHZ) } \\
\text { (continuous) }\end{array}$ & & & & $0.99(0.63-1.56)$ & $1.22(0.73-2.06)$ \\
\hline \multicolumn{6}{|l|}{ Immediate factors } \\
\hline \multirow[t]{2}{*}{ Child dietary diversity } & Low & $61(76.3)$ & $18(66.7)$ & 1 & 1 \\
\hline & $\begin{array}{l}\text { Medium } \\
\text { and high }\end{array}$ & $19(23.8)$ & $9(33.3)$ & $1.60(0.62-4.16)$ & $1.79(0.57-5.58)$ \\
\hline \multirow{3}{*}{$\begin{array}{l}\text { Meal frequency } \\
\text { (continuous) } \\
\text { Green vegetable } \\
\text { consumption per week }\end{array}$} & & & & $1.48(0.81-2.70)$ & $1.80(0.89-3.62)$ \\
\hline & 0 intake & $19(23.8)$ & $7(25.9)$ & 1 & 1 \\
\hline & $\begin{array}{l}\text { At least } \\
\text { once }\end{array}$ & $61(76.2)$ & $20(74.1)$ & $0.63(0.24-1.64)$ & $0.59(0.19-1.83)$ \\
\hline
\end{tabular}


Figure 1

Percentage of household dietary consumption in the last 24 hours 


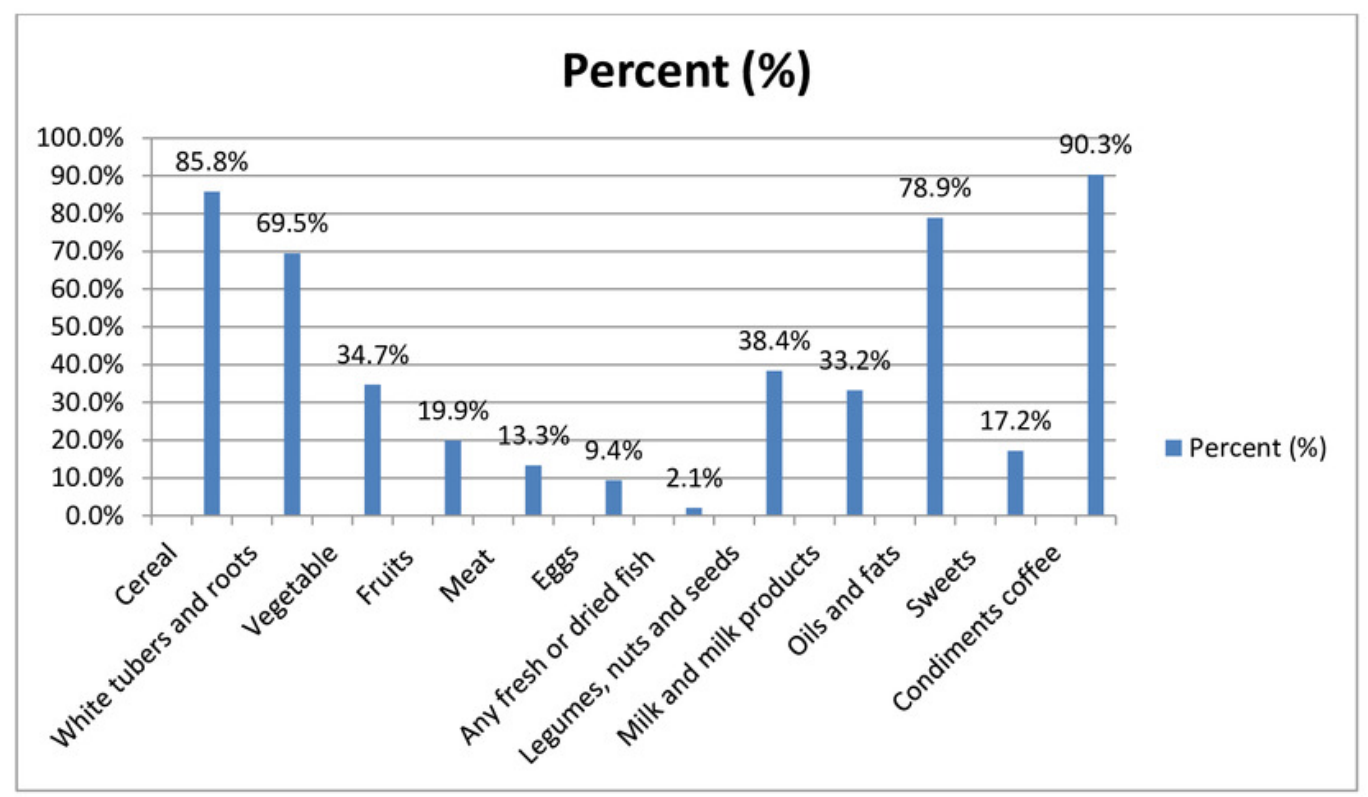

